pp. $41-50$

\title{
ANALISIS KINERJA SIMPANG TIGA TAK BERSINYAL
}

\author{
(Studi Kasus Simpang Lamlo Kabupaten Pidie)
}

\author{
Helwiyah Zain ${ }^{1}$, Meliyana ${ }^{2}$, Muhaimin ${ }^{3}$ \\ ${ }^{1), 2), 3)}$ Program Studi Teknik Sipil, Fakultas Teknik, Universitas Abulyatama \\ Jl. Blang Bintang Lama Km 8,5 Lampoh Keude Aceh Besar, \\ email: ocudma2h@gmail.com, yana_meli@google.com
}

\begin{abstract}
Simpang Lamlo is one of No-Signal Three-way Junctions in National Road from Banda Aceh to Medan as a Main road and is connected directly to the Cross-Regional Road that is from Beureuneun to Geumpang as the Minor Road and vice versa. The purpose of this study is to analyze the performance of the No-Signal Three-Way Junctions by using the Indonesian Highway Capacity Manual 1997. Data required in this study are primary and secondary data. The primary data is in the form of the condition data of traffic, intersection geometric, and environment. Secondary data includes the population growth and the map of the road network. Traffic data were collected by using video recording on Monday, Wednesday and Saturday at 7.00 a.m. - 9.00 a.m., 12.00 p.m. - 2.00 p.m and 5.00 p.m. - 7.00 pm. These data were processed by using Microsoft Excel based on MKJI 1997 and and the results were made in the form of tables and graphics. From the tables and graphics, it could be known for the traffic volume, composition, and the peak hours occured in the intersections. The calculation on the peak hour with the current highest peak is on Monday, 5.00 p.m. - 6:00 p.m. in which the traffic volume at the intersection is 2737 (smp / hour). The capacity value of the existing condition in Simpang Lamlo is 2762 (smp / hour). The traffic delay in the intersection is 11,63 (det / smp). The degree of saturation at the existing condition is 0.99, higher than the provision in Indonesian Highway Capacity Manual which is 0,75. The intersection delay value is 15.64 (det / smp) and the queue chance at the intersection is $39,43 \%$ to $77,98 \%$,
\end{abstract}

Keywords : no-signal three-way junction, degree of saturation, delay, and queue chance.

\begin{abstract}
Abstrak: Simpang Lamlo adalah salah satu Simpang Tiga Tak Bersinyal yang berada di lintas jalan Nasional Banda Aceh ke Medan sebagai jalan Utama dan terhubung langsung dengan jalan lintas Provinsi yaitu jalan dari Beureuneun ke Geumpang sebagai jalan Minor begitu juga sebaliknya. Tujuan penelitian ini adalah untuk menganalisa kinerja simpang tiga tak bersinyal dengan menggunakan Manual Kapasitas Jalan Indonesia 1997. Data yang diperlukan dalam penelitian ini berupa data primer dan data sekunder. Adapun data primer berupa data kondisi arus lalu lintas, geometrik persimpangan dan kondisi lingkugan. Data sekunder meliputi pertumbuhan penduduk dan peta jaringan jalan. Pengumpulan data lalu lintas dilakukan dengan menggunakan rekaman video pada hari Senin, Rabu dan Sabtu pada jam pagi 07.00-09.00, siang 12.00-14.00 dan sore 17.00-19.00. Data ini diolah menggunakan Microsoft Excel berdasarkan manual MKJI 1997 dan hasil yang diperoleh dibuat dalam bentuk tabel dan grafik. Dari tabel dan grafik tersebut dapat diketahui volume lalu lintas, komposisi lalu lintas, serta jam puncak yang terjadi pada persimpangan tersebut. Hasil perhitungan pada jam puncak dengan arus tertinggi yaitu pada hari senin jam 17.00-18.00 yang diperoleh volume arus lalu lintas pada persimpangan ini sebesar 2737 (smp/jam). Nilai kapasitas kondisi eksisting pada Simpang Lamlo yaitu 2762 (smp/jam). Tundaan lalu lintas simpang sebesar 11,63 (det/smp). Nilai derajat kejenuhan pada kondisi eksisting sebesar 0,99 melebihi ketetapan Manual Kapasitas Jalan Indonesia yaitu 0,75 . Nilai tundaan simpang yaitu 15,64 (det/smp) dan peluang antrian simpang sebesar 39,43\% sampai dengan 77,98\%,
\end{abstract}

Kata kunci : simpang tiga tak bersinyal, derajat kejenuhan, tundaan dan peluang antrian. 
Simpang Lamlo terletak di Kecamatan Mutiara Kabupaten Pidie yang berada diantara Kota Sigli dengan Kota Beureunuen juga merupakan salah satu pusat ekonomi terbesar di Kabupaten Pidie. Simpang Lamlo berada pada lintas jalan Nasional Banda Aceh-Medan dan terhubung langsung dengan jalan lintas provinsi yaitu dari Kabupaten Pidie ke Kota Banda Aceh dan Kabupaten Aceh Barat. Pada simpang tiga tak bersinyal ini sering terjadi konflik antara kendaraan yang berbeda kepentingan, baik asal maupun tujuan. Berkaitan dengan hal tersebut analisa persimpangan tak bersinyal sangat diperlukan, sehingga tidak menimbulkan akses yang lebih buruk, misalnya kemacetan lalu-lintas. Kemacetan lalu-lintas menimbulkan kerugian yang besar bagi masyarakat yaitu biaya yang makin tinggi akibat pemborosan bahan bakar, polusi udara, kebisingan dan memperlambat arus barang dan jasa.

Sebelum dilakukan penelitian terlebih dahulu dilakukan pengamatan dilapangan. Berdasarkan survei di lapangan kendaraan terlihat di setiap lengannya baik pada pagi hari, siang hari, maupun sore hari. Tundaan kendaraan tersebut disebabkan oleh banyaknya jumlah kendaraan yang ingin melintas dari berbagai arah. Untuk mendapat solusi dalam mengurangi kemacetan, penulis melakukan penelitian pada jalan ini. Lokasi penelitian ini adalah simpang Lamlo, kecamatan Mutiara, Kabupaten Pidie.

Berdasarkan uraian yang disebutkan diatas, maka rumusan masalah dalam kajian ini adalah bagaimana kinerja simpang dilihat dari sisi kapasitas, derajat kejenuhan, tundaan dan peluang antrian, sehingga dapat memberikan hasil dari analisa simpang guna meningkatkan kinerja Simpang Tiga Lamlo.

Penelitian ini bertujuan untuk menganalisis kinerja simpang tiga tak bersinyal pada simpang Lamlo Kabupaten Pidie. Kinerja simpang yang dianalisis yaitu kapasitas, derajat kejenuhan, tundaan dan peluang antrian. berdasarkan Manual Kapasitas Jalan Indonesia (MKJI, 1997). Ruang lingkup penelitian ini adalah analisa kinerja simpang tiga tak bersinyal dan hasilnya dapat memberi kesimpulan dan saran terkait kinerja persimpangan tersebut

\section{KAJIAN PUSTAKA}

Menurut Khisty J.C., \& B. Kent Lall, (2005-274), persimpangan jalan didefinisikan sebagai daerah umum di mana ada dua jalan atau lebih bergabung termasuk jalan dan fasilitas tepi jalan untuk pergerakan lalu-lintas di dalamnya. Persimpangan sebidang dapat dikelompokkan menurut cabangnya yaitu: pertemuan sebidang bercabang tiga, pertemuan sebidang bercabang empat, pertemuan sebidang bercabang banyak. Menurut pengaturannya, persimpangan sebidang dibagi menjadi dua yaitu persimpangan tak sinyal dan persimpangan dengan sinyal. 


\section{Tipe simpang}

Menurut Anonim (1997: 2-27), tipe simpang merupakan jumlah lengan simpang dan jumlah lajur pada jalan utama dan jalan minor pada simpang tersebut. Jumlah lengan yaitu jumlah lengan dengan lalu-lintas masuk atau keluar bahkan keduanya.

Pada umumnya simpang tak bersinyal dengan pengaturan hak jalan (prioritas dari sebelah kiri) digunakan didaerah permukiman, perkotaan dan daerah pedalaman atau persimpangan antara jalan lokal dengan arus lalu lintas rendah. Kode tipe simpang dapat dilihat pada Tabel 1 dibawah ini:

\section{Tabel 1. Kode Tipe Simpang}

\begin{tabular}{|c|c|c|c|}
\hline $\begin{array}{c}\text { Kode } \\
\text { IT }\end{array}$ & $\begin{array}{c}\text { Jumlah lengan } \\
\text { simpang }\end{array}$ & $\begin{array}{c}\text { Jumlah lajur } \\
\text { jalan minor }\end{array}$ & $\begin{array}{c}\text { Jumlah lajur } \\
\text { jalan utama }\end{array}$ \\
\hline 322 & 3 & 2 & 2 \\
324 & 3 & 2 & 4 \\
342 & 3 & 4 & 2 \\
422 & 4 & 2 & 2 \\
424 & 4 & 2 & 4 \\
\hline
\end{tabular}

Sumber : (Anonim, $1997: 3-32$ )

\section{Arus lalu lintas}

Menurut Anonim (1997: 2-6), arus lalu lintas adalah jumlah unsur lalu lintas yang melalui titik tak tergangu di hulu pendekat per satu waktu, dinyatakan dalam satuan kend/jam atau smp/jam. Komposisi pergerakan lalu-lintas yang melewati persimpangan dibagi 4 bagian yaitu:

1. Light Vehicle (LV), yaitu kendaraan ringan yang beroda empat dengan dua as berjarak 2-3 meter (termasuk kendaraan penumpang, mikro bis, pick up, dan truck kecil).
2. Heavy Vahicle (HV), yaitu kendaraan berat beroda lebih dari empat roda dengan jarak as 3-4 meter, termasuk bis, truk 2 as, truck 3 as dan sejenisnya.

3. Motor Cycle (MC), yaitu kendaraan bermotor beroda dua atau tiga seperti becak motor dan sepeda motor.

4. Unmotorized (UM), yaitu kendaraan tidak bermotor beroda dua atau tiga seperti becak, sepeda, kereta dorong dan pejalan kaki.

Arus lalu-lintas $(\mathrm{Q})$ untuk setiap gerakan (belok-kiri QLT, lurus QST dan belok-kanan QRT) dikonversi dari kendaraan per-jam menjadi satuan mobil penumpang (smp) perjam dengan menggunakan ekivalen mobil penumpang (emp) untuk masing-masing pendekat terlindung dan terlawan, seperti terlihat pada Tabel berikut ini.

Tabel 2. Faktor Ekivalen Mobil Penumpang

\begin{tabular}{|l|l|}
\hline Jenis Kendaraan & Emp \\
\hline Kendaraan Ringan (LV) & 1,0 \\
Kendaraan Berat (HV) & 1,3 \\
Sepeda Motor (MC) & 0,5 \\
\hline
\end{tabular}

Sumber: Anonim, (1997: 3-46)

Berdasarkan (Anonim, 1997 : 3-2), untuk megetahui nilai arus lalulintas dapat digunakan persamaan 1 berikut:

$$
\begin{aligned}
\mathrm{Q}= & (\mathrm{QLV} \times \mathrm{empLV})+(\mathrm{QHV} \times \mathrm{empHV})+ \\
& (\mathrm{QMC} \times \mathrm{empMC})
\end{aligned}
$$




\section{Kapasitas}

Menurut Anonim (1997: 2-7), kapasitas adalah arus lalu-lintas maksimum yang dapat dipertahankan pada kondisi tertentu (geometrik, arus lalu-lintas dan lingkungan), kapasitas total untuk seluruh lengan simpang adalah hasil perkalian antara kapasitas dasar (Co) yaitu kapasitas pada kondisi tertentu (ideal) dan faktor-faktor penyesuaian (F) dengan memperhitungkan kondisi lapangan terhadap kapasitas. Untuk megetahui nilai kapasitas dapat digunakan persamaan (2) berikut :

$\mathrm{C}=\mathrm{Co} \times \mathrm{FW} \times \mathrm{FM} \times \mathrm{FCS} \times \mathrm{FRSU} \times \mathrm{FLT} \times$ $\mathrm{FRT} \times \mathrm{FMI}$

\section{Kapasitas Dasar (Co)}

Menurut Anonim (1997: 3-7), kapasitas dasar merupakan kapasitas persimpangan jalan total untuk suatu kondisi tertentu yang telah ditentukan sebelumnya (kondisi dasar), kapasitas dasar (smp/jam) ditentukan oleh tipe simpang. Besarnya kapasitas dasar dapat dilihat pada Tabel 3 berikut ini.

\section{Tabel 3. Kapasitas Dasar Menurut Tipe Simpang}

\begin{tabular}{|c|c|}
\hline Tipe simpang IT & Kapasitas dasar smp/jam \\
\hline 322 & 2700 \\
342 & 2900 \\
324 atau 344 & 3200 \\
422 & 2900 \\
424 atau 444 & 3400 \\
\hline
\end{tabular}

Sumber: Anonim (1997: 3-33)

\section{Faktor penyesuaian lebar masuk (Fw)}

Menurut Anonim (1997: 3-7), faktor penyesuaian lebar masuk (Fw) ini merupakan faktor penyesuaian untuk kapasitas sehubungan dengan lebar masuk persimpangan jalan, faktor penyesuaian lebar pendekat $(\mathrm{Fw})$ masuk ini didasarkan pada lebar sebuah pendekat suatu simpang atau $\mathrm{W}_{-1}$, Faktor ini berbeda untuk setiap tipe simpang. Untuk lebih jelasnya faktor penyesuaian lebar pendekat (Fw) dapat dilihat pada Tabel 4 berikut ini.

Tabel 4. Faktor Penyesuaian Lebar Pendekat

\begin{tabular}{|c|c|}
\hline Tipe Simpang & $\begin{array}{c}\text { Faktor Penyesuaian } \\
\text { Lebar Pendekat }\end{array}$ \\
\hline 422 & $0,70+0,0866 \mathrm{~W}_{1}$ \\
\hline 424 ata 444 & $0,61+0,0740 \mathrm{~W}_{1}$ \\
\hline 322 & $0,73+0,0760 \mathrm{~W}_{1}$ \\
\hline 324 atau 344 & $0,62+0,0646 \mathrm{~W}_{1}$ \\
\hline 342 & $0,67+0,0698 \mathrm{~W}_{1}$ \\
\hline
\end{tabular}

Sumber : Anonim (1997: 3-7)

Faktor penyesuaian median jalan $\operatorname{utama}\left(\mathbf{F}_{M}\right)$

Menurut Anonim (1997: 3-7), faktor penyesuaian median jalan utama $\left(\mathrm{F}_{\mathrm{M}}\right)$ ini merupakan faktor penyesuaian untuk kapasitas dasar sehubungan dengan tipe median jalan utama. Tipe median jalan utama merupakan klasifikasi median jalan utama berdasarkan ketersediaan dan lebar jalan utama, faktor ini hanya digunakan pada jalan utama dengan jumlah lajur empat. Faktor penyesuaian median jalan utama dapat dilihat pada tabel berikut ini. 
Tabel 5. Faktor Penyesuaian Median Jalan Utama

\begin{tabular}{|l|c|c|}
\hline \multicolumn{1}{|c|}{ Uraian } & Median & $\begin{array}{c}\text { Faktor } \\
\text { Penyesuaian } \\
\text { Median }\end{array}$ \\
\hline Tidak ada median jalan utama & Tidak ada & 1,00 \\
\hline Ada median jalan utama, lebar $<3 \mathrm{~m}$ & Sempit & 1,05 \\
\hline Ada median jalan utama, lebar $\geq 3 \mathrm{~m}$ & Lebar & 1,20 \\
\hline
\end{tabular}

Sumber: Anonim, (1997: 3-34)

\section{Faktor penyesuaian ukuran kota $\left(\mathbf{F}_{\mathrm{CS}}\right)$}

Menurut Anonim (1997: 3-7), faktor penyesuaian ukuran kota City size (CS) ini hanya dipengaruhi oleh variabel jumlah penduduk suatu kota dalam satuan juta. Seperti tercantum dalam Tabel berikut ini.

Tabel 6. Faktor Penyesuaian Ukuran Kota

\begin{tabular}{|l|c|c|}
\hline Ukuran kota & Penduduk Juta & $\begin{array}{c}\text { Faktor penyesuaian } \\
\text { ukuran kota }\end{array}$ \\
\hline Sangat kecil & $<0,1$ & 0,82 \\
\hline Kecil & $0,1-0,5$ & 0,88 \\
\hline Sedang & $0,5-1,0$ & 0,94 \\
\hline Besar & $1,0-3,0$ & 1,00 \\
\hline Sangat besar & $>3,0$ & 1,05 \\
\hline
\end{tabular}

Sumber: Anonim, (1997: 3-34)

\section{Derajat kejenuhan (DS)}

Menurut Anonim (1997: 5-19), derajat kejenuhan didefinisikan sebagai rasio arus terhadap kapasitas untuk suatu pendekat. Nilai derajat kejenuhan untuk simpang tak bersinyal adalah $<0,85$ yang menunjukan apakah simpang tersebut mempunyai masalah atau tidak. Berdasarkan Anonim (1997: 3-11), nilai kejenuhan dapat diperoleh dari persamaan berikut ini.
$\mathrm{DS}=\mathrm{Qsmp} / \mathrm{C}$

Dimana :

DS $=$ Derajat kejenuhan

Qsmp $=$ Arus lalu lintas

$\mathrm{C} \quad=$ Kapasitas

\section{Tundaan}

Menurut Anonim (1997: 3-6), tundaan (D) adalah waktu tempuh tambahan untuk melewati simpang bila dibandingkan situasi tanpa simpang yang terdiri dari tundaan lalulintas (DT) dan tundaan geometrik (DG). Tundaan lalu-lintas terdiri dari empat tundaan yaitu:

1. Tundaan lalu-lintas simpang $\left(\mathrm{DT}_{\mathrm{I}}\right)$

Tundaan lalu-lintas simpang adalah tundaan lalu-lintas, rata-rata untuk semua kendaraan bermotor yang masuk simpang. Berdasarkan Anonim (1997: 340). Tundaan lalu-lintas simpang dapat dihitung dengan menggunakan persamaan berikut.

Untuk DS $\leq 0.6$ :

$\mathrm{DT}=2+(8,2078 \times \mathrm{DS})$

Sedangkan, DS $\geq 0,6$ :

$\mathrm{DT}=\frac{1,0504}{0,2742-(0,2042 \times \mathrm{DS})}[(1-\mathrm{DS}) \times 2]$

2. Tundaan lalu-lintas jalan utama

Tundaan lalu-lintas jalan utama adalah tundaan lalu-lintas rata-rata semua kendaraan bermotor yang masuk persimpangan dari jalan utama. Berdasarkan Anonim (1997: 3-41), tundaan lalu-lintas jalan utama dapat dihitung dengan menggunakan persamaan berikut ini. 
Untuk Ds $\leq 0.6$

$\mathrm{DT}=1,8+(5,8235 \times \mathrm{DS})-[(1-\mathrm{DS}) \times 1,8]$

Sedangkan, DS $\geq 0,6$

$\mathrm{DT}=\frac{1,05034}{0,367-(0,2046 \times \mathrm{DS})}-[(1-\mathrm{DS}) \times 1,8]$

3. Tundaan lalu-lintas jalan minor

Tundaan lalu-lintas jalan minor adalah tundaan lalu-lintas jalan minor rata-rata, ditentukan berdasarkan tundaan simpang rata-rata dan tundaan jalan utama rata-rata dan tundaan jalan utama rata-rata. Berdasarkan Anonim (1997: 3-41), tundaan lalu-lintas jalan minor dapat dihitung dengan menggunakan persamaan berikut ini.

$\mathrm{DT}_{\mathrm{MI}}=\left[\frac{(\mathrm{QTOT} \times \mathrm{DTI}-\mathrm{QMA} \times \mathrm{DTMA})}{\mathrm{QMI}}\right]$

4. Tundaan geometrik simpang

Tundaan geometrik simpang adalah tundaan geometrik rata-rata seluruh kendaraan bermotor yang masuk simpang. DG dihitung dengan menguunakan persamaan dibawah ini.

Untuk DS $<1,0$

$\mathrm{DG}=(1-\mathrm{DS}) \times\left(\mathrm{P}_{\mathrm{T}} \times 6+\left(1-\mathrm{P}_{\mathrm{T}}\right) \times 3\right)+\mathrm{DS} \times 4$ $(\operatorname{det} / \mathrm{smp})$

Untuk DS $\geq 1,0$

$$
\mathrm{DG}=4
$$

Jadi tundaan simpang merupakan penjumlahan antara tundaan geometrik simpang dan tundaan lalu-lintas simpang. Berdasarkan Anonim (1997: 3-42) tundaan simpang dapat dihitung dengan menggunakan persamaan berikut.

$\mathrm{D}=\mathrm{DG}+\mathrm{DT}_{\mathrm{I}}(\operatorname{det} / \mathrm{smp})$

\section{Peluang antrian}

Berdasarkan Anonim (1997: 3-42), nilai peluang antrian dapat ditentukan dari hubungan empiris antara peluang antrian dan derajat kejenuhan. Peluang antrian dengan batas atas dan batas bawah dapat peroleh dengan menggunakan persamaan berikut.

Batas atas :

$$
\begin{aligned}
\mathrm{Q}_{\mathrm{p} \%}= & (47,71 \times \mathrm{DS})+\left(24,68 \times \mathrm{DS}^{2}\right) \\
& +\left(56,47 \times \mathrm{DS}^{3}\right)
\end{aligned}
$$

Batas bawah :

$$
\begin{aligned}
\mathrm{Q}_{\mathrm{p} \%}= & (9,02 \times \mathrm{DS})+\left(20,66 \times \mathrm{DS}^{2}\right) \\
& +(10,49 \times \mathrm{DS} 3)
\end{aligned}
$$

\section{METODE PENELITIAN}

Metode penelitian ini dilakukan dengan cara pengambilan data dengan menggunakan rekaman kamera yang dipasang di persimpangan tersebut. Sebelum proses pengambilan data dilapangan, terlebih dahulu direncanakan jadwal pengamatan untuk menentukan hari dan jam pengambilan data lalu lintas. Data yang digunakan pada penelitian ini adalah data primer dan sekunder. Adapun data primer adalah kondisi arus lalu lintas, geometrik persimpangan dan kondisi lingkungan, sedangkan data sekunder berupa pertumbuhan penduduk dan peta jaringan jalan. Data tersebut diolah berdasarkan Manual Kapasitas Jalan Indonesia (MKJI, 1997).

Data yang diambil pada penelitian ini meliputi data volume lalu lintas, berdasarkan pengamatan di lapangan, pengambilan data 
dilakukan pada hari Sabtu 14 November, Senin 16 November, dan Rabu 18 November 2015, masing-masing pada jam pagi 07.0009.00, siang pukul 12.00-14.00, dan sore pukul 17.00-19.00. Data volume lalu lintas dikumpulkan kemudian dikonversikan kedalam smp/jam, yaitu dengan mengalikan volume lalu lintas dalam kend/jam dengan faktor ekivalen mobil penumpang yang berpedoman pada Manual Kapasitas Jalan Indonesia (MKJI 1997).

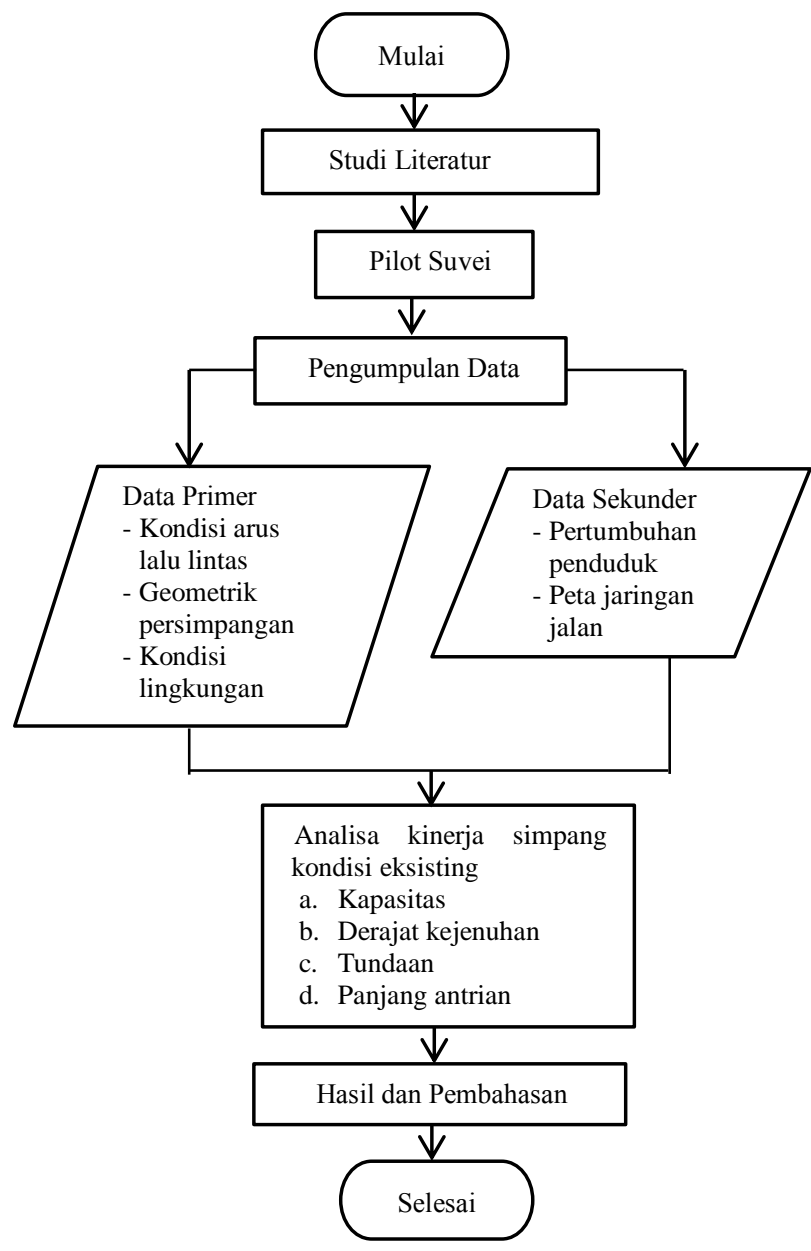

Gambar 1. Bagan Alir Proses Penelitian

\section{HASIL PEMBAHASAN}

\section{Kondisi geometrik jalan}

Simpang Lamlo memiliki tiga lengan dengan masing-masing mempunyai dua jumlah lajur, lengan arah dari Banda Aceh dan Medan merupakan jalan Utama dan arah dari Geumpang merupakan jalan minor, ruas lebar efektif masing-masing pendekat pada persimpangan lamlo dapat dilihat pada Tabel 7 berikut:

Tabel 7. Kondisi Geometrik masing-masing Pendekat

\begin{tabular}{|l|l|l|l|}
\hline No & Pendekat (Arah) & \multicolumn{1}{|c|}{$\begin{array}{c}\text { Ruas lebar } \\
\text { efektif }(\mathrm{m})\end{array}$} & $\begin{array}{l}\text { Kondisi } \\
\text { jalan }\end{array}$ \\
\hline 1 & A (Geumpang) & $6,3 \mathrm{~m}$ & Minor \\
\hline 2 & B (Banda Aceh) & $7,97 \mathrm{~m}$ & Utama \\
\hline 3 & C (Medan) & $8,05 \mathrm{~m}$ & Utama \\
\hline
\end{tabular}

\section{Volume lalu lintas}

Berdasarkan hasil perhitungan Volume lalu lintas dalam tiga hari tersebut diperoleh jam puncak yaitu pada hari senin periode jam 17.00 - 18.00 sebesar 2737 smp/jam. Pada hari Rabu arus lalu lintas puncak terjadi pada jam sibuk sore periode jam 17.00-18.00 sebesar 2396 smp/jam. Kemudian pada hari Sabtu arus lalu lintas puncak terjadi pada jam sibuk siang pukul 13.00-14.00 WIB sebesar 2406 smp/jam. Jam puncak pada tiga hari pegamatan dapat dilihat dalam Tabel berikut ini.

Arus lalu lintas tersebut akan dijadikan parameter untuk menganalisa kinerja simpang tiga tak bersinyal Simpang Lamlo, Arus lalu lintas simpang dapat dilihat pada pada Tabel berikut ini. 
Tabel 8. Analisa Arus Lalu Lintas Simpang Lamlo Berdasarkan MKJI 1997

\begin{tabular}{|c|c|c|c|c|c|c|}
\hline \multicolumn{2}{|c|}{ Arus lalu lintas } & $(\mathrm{LV})$ & $(\mathrm{HV})$ & $(\mathrm{MC})$ & (MV) & kendaraan tak \\
\hline \multicolumn{2}{|c|}{$\begin{array}{r}\text { Pendekat Arah } \\
\text { ( Dari Aarah) }\end{array}$} & $\begin{array}{l}\text { Kend } \\
\text { / jam }\end{array}$ & Kend / jam & Kend / jam & $\mathrm{Smp} / \mathrm{jam}$ & bermotor \\
\hline \multirow{2}{*}{$\begin{array}{l}\text { JL. Minor A } \\
\text { (Geumpang) }\end{array}$} & LT & 49 & 38 & 105 & 192 & 8 \\
\hline & RT & 54 & 21 & 229 & 303 & 4 \\
\hline \multicolumn{2}{|l|}{ J1. Minor total } & 103 & 59 & 334 & 595 & 12 \\
\hline \multirow{2}{*}{$\begin{array}{l}\text { JL. Utama B } \\
\text { (Banda aceh) }\end{array}$} & $\mathrm{ST}$ & 277 & 39 & 614 & 930 & 16 \\
\hline & RT & 57 & 14 & 97 & 168 & 31 \\
\hline \multicolumn{2}{|l|}{ J1. Utama Total } & 334 & 53 & 711 & 108 & 47 \\
\hline \multirow{2}{*}{$\begin{array}{l}\text { JL. Utama C } \\
\text { (Medan) }\end{array}$} & $\overline{\mathrm{LT}}$ & 67 & 14 & 225 & 306 & 14 \\
\hline & ST & 291 & 22 & 525 & 838 & 15 \\
\hline \multicolumn{2}{|l|}{ J1. Utama Total } & 358 & 36 & 750 & 1144 & 29 \\
\hline \multicolumn{2}{|c|}{ JL. Utama Total B+C } & 629 & 90 & 1460 & 2242 & 76 \\
\hline \multirow[t]{3}{*}{ Utama + Minor } & LT & 116 & 52 & 330 & 498 & 22 \\
\hline & $\mathrm{ST}$ & 568 & 61 & 1139 & 1768 & 31 \\
\hline & RT & 111 & 35 & 326 & 472 & 35 \\
\hline \multicolumn{2}{|c|}{ Utama + Minor Total } & 795 & 148 & 1794 & 2737 & 88 \\
\hline \multicolumn{4}{|c|}{ Rasio Jl.Minor / (Jl.Utama+minor) total } & 0,181 & UM/MV & 0,019 \\
\hline
\end{tabular}

Tabel 9. Volume Lalu Lintas Tiga Hari Pengamatan

\begin{tabular}{||c|c|c|c||}
\hline \multirow{2}{*}{ Waktu } & \multicolumn{3}{|c||}{ Arus lalu lintas (smp/jam) } \\
\cline { 2 - 4 } & Senin & Rabu & Sabtu \\
\hline \hline $07.00-08.00$ & 2296 & 2155 & 2067 \\
\hline $08.00-09.00$ & 2379 & 2274 & 2320 \\
\hline $12.00-13.00$ & 2271 & 2268 & 2150 \\
\hline 13.00 .14 .00 & 2422 & 2386 & 2406 \\
\hline $17.00-18.00$ & 2737 & 2396 & 2282 \\
\hline $18.00-19.00$ & 2493 & 2337 & 2380 \\
\hline \hline
\end{tabular}

\section{Kapasitas}

Kapasitas Simpang Lamlo yaitu sebesar $2762 \mathrm{smp} / \mathrm{jam}$ yang diperoleh dari persamaan

2. Penentuan nilai kapasitas simpang meliputi faktor lebar pendekat, tipe simpang dan faktor penyesuaian kapasitas, yaitu:
1. Lebar pendekat rata-rata

Lebar pendekat rata-rata Simpang Lamlo adalah 3,73 meter yang diperoleh dari hasil perbandingan lebar keseluruhan pendekat dengan jumlah lengan simpang.

2. Tipe simpang

Tipe Simpang Lamlo yaitu 322 dengan asumsi memiliki tiga lengan dan mempunyai dua lajur jalan utama dan dua lajur jalan minor, penentuan lebar pendekat dan tipe simpang dapat dilihat pada tabel berikut. 
Tabel 10. Faktor Penyesuaian Tipe Simpang

\begin{tabular}{|c|l|c|}
\hline No & \multicolumn{2}{|c|}{ Lebar pendekat dan tipe simpang } \\
\hline 1 & Jumlah lengan simpang (m) & 3 \\
\hline 2 & Lebar pendekat Jalan minor Wa (m) & 3,40 \\
\hline 3 & Lebar pendekat Jalan minor Wad (m) & 3,78 \\
\hline 4 & Lebar pendekat Jalan utama Wb (m) & 4,06 \\
\hline 5 & Lebar pendekat Jalan utama Wc (m) & 4.06 \\
\hline 6 & Lebar pendekat Jalan utama Wbc (m) & 4,06 \\
\hline 7 & Lebar pendekat rata-rata (m) & 3,84 \\
\hline 8 & Jumlah lajur jalan minor & 2 \\
\hline 9 & Jumlah lajur jalan utama & 322 \\
\hline 10 & Tipe simpang & \\
\hline
\end{tabular}

Kapasitas dasar untuk tipe simpang 322 tak bersinyal berdasarkan ketetapan pada Manual Kapasitas Jalan Indonesia (MKJI), yaitu sebesar 2700. Lebar pendekat rata-rata sebesar 3,84 diperoleh dari dasar empiris Manual Kapasitas Jalan Indonesia (MKJI), yaitu untuk menentukan faktor median jalan utama berdasarkan tipe median jalan utama,

3. Faktor ukuran Kota

Faktor ukuran kota ditentukan berdasarkan jumlah penduduk Kabupaten Pidie dan Pidie Jaya. Nilai penyesuaian ukuran kota (Fcs) yaitu 0.94 dengan kategori kota sedang.

4. Hambatan samping

Hambatan samping pada persimpangan Simpang Lamlo sebesar (1) dengan anggapan bahwa $(\mathrm{empUM}=0)$.

5. Faktor penyesuaian kiri

Faktor penyesuaian belok kiri (Flt) ditentukan dengan menggunakan rentang dasar empiris yaitu sebesar $(1,13)$.

6. Faktor penyesuaian belok kanan

Faktor penyesuaian belok kanan (Frt) diperoleh dengan menggunakan rentang dasar empiris yaitu sebesar $(0,93)$.

7. Rasio arus jalan minor total (Fmi)

Rasio arus jalan minor total (Fmi) untuk persimpangan Lamlo yaitu sebesar $(1,01)$ dihitung berdasarkan tipe simpang dan rasio minor.

Adapun nilai faktor penyesuaian kapasitas pada persimpangan tak bersinyal Simpang Lamlo dapat dilihat berdasarkan Tabel 11 berikut ini:

Tabel 11. Faktor Penyesuaian Kapasitas (F)

\begin{tabular}{|c|l|c|c|}
\hline No & \multicolumn{2}{|c|}{ Perilaku lalu lintas } & Nilai \\
\hline 1 & Kapasitas dasar & Co & 2700 \\
\hline 2 & Lebar pendekat rata-rata & Fw & 1,02 \\
\hline 3 & Median jalan utama & Fm & 1 \\
\hline 4 & Ukuran kota & Fcs & 0.94 \\
\hline 5 & Hambatan samping & Frsu & 1 \\
\hline 6 & Belok kiri & Flt & 1.13 \\
\hline 7 & Belok kanan & Frt & 0.93 \\
\hline 8 & Rasio arus jalan minor/ total & Fmi & 1,01 \\
\hline 9 & Kapasitas smp/jam & C & 2763 \\
\hline
\end{tabular}

\section{Derajat Kejenuhan (DS)}

Derajat kejenuhan (DS) pada persimpangan Lamlo yaitu sebesar $(0,99)$ yang dihasilkan dari perbandingan nilai arus lalu lintas total dengan nilai kapasitas.

\section{Tundaan simpang}

Tundaan lalu lintas pada persimpangan Lamlo yaitu sebesar $(11,63) \mathrm{det} / \mathrm{smp}$ seperti yang terlihat pada tabel berikut yang diperoleh dari penjumlahan nilai tundaan geometrik simpang yaitu sebesar $4 \operatorname{det} / \mathrm{smp}$ dengan tundaan lalu lintas simpang sebesar $(11,63) \operatorname{det} / \mathrm{smp}$. 


\section{Peluang antrian}

Peluang antrian pada Simpang Lamlo yaitu $39,43 \%$ sampai dengan $77,98 \%$ yang dihasilkan dari hubungan empiris antara peluang antrian dan derajat kejenuhan pada batas atas dan batas bawah, adapun nilai batas atas yaitu sebesar 39,43\% dan batas bawah sebesar 77,98\%, Perilaku lalu lintas simpang dapat dilihat pada tabel dibawah ini.

Tabel 12. Perilaku Lalulitas Simpang

\begin{tabular}{|c|l|c|c|}
\hline No & \multicolumn{2}{|c|}{ Perilaku lalu lintas } & Nilai \\
\hline 1 & Arus lalu lintas & Q & 2737 \\
\hline 2 & Derajat kejenuhan & DS & 0,99 \\
\hline 3 & Tundaan lalu lintas simpang & DT1 & 11,63 \\
\hline 4 & Tundaan lalu lintas jalan utama & Dma & 11,06 \\
\hline 5 & Tundaan lalu lintas jalan minor & Dmi & 11,25 \\
\hline 6 & Tundaan geometrik simpang & DG & 4 \\
\hline 7 & Tundaan simpang & D & 15,64 \\
\hline \multirow{2}{*}{8} & \multirow{2}{*}{ Peluang antrian $(\%)$} & Qp atas & 39,43 \\
\cline { 3 - 4 } & & Qp bawah & 77,98 \\
\hline
\end{tabular}

\section{KESIMPULAN DAN SARAN}

\section{Kesimpulan}

Hasil pengamatan di lapangan untuk 3 (tiga) hari pengamatan, didapatkan 3 (tiga) jam puncak tertinggi untuk masing-masing periode pagi, siang, sore. Berdasaran hasil perhitungan dan pengolahan data dari jam puncak tertinggi yaitu pada jam puncak sore hari Senin tanggal 16 November 2015 dapat diambil kesimpulan sebagai berikut:

1. Berdasarkan hasil penelitian diperoleh jam puncak (peak hours) dari tiga hari pengamatan terjadi pada hari Senin tanggal 16 November 2015 yaitu pada jam 17.00-18.00.

2. Kapasitas simpang Lamlo pada kondisi eksisting melewati nilai jenuh, hal ini ditandai dengan nilai derajat kejenuhan (DS) sebesar 0,99 det/smp
3. Nilai kapasitas (C) pada persimpangan Lamlo adalah sebesar 2762 smp/jam

4. Nilai tundaan lalu lintas (DT) adalah sebesar 15,64 det/smp

5. Peluang antrian sebesar $39,43 \%$ sampai dengan $77,98 \%$

\section{Saran}

Derajat kejenuhan sebesar 0.99 lebih besar dari yang ditetapkan dalam MKJI 1997 yaitu 0.75 menandakan simpang tersebut perlu adanya peningkatan kapasitas. Perencanaan bundaran atau traffick light diperlukan untuk meningkatkan kapasitas simpang. Selain itu diperlukan perencanaan ulang lebar pendekat simpang untuk mengurangi nilai tundaan dan peluang antrian simpang.

\section{DAFTAR PUSTAKA}

Anonim, 1997, Manual Kapasitas Jalan Indonesia (MKJI), Direktorat Jendral Bina Marga, Departemen Pekerjaan Umum RI, Jakarta.

Anonim, 2000, Highway Capacity Manual (HCM), Transportation Research Boards, USA.

Bukhari, R.A., dan Sofyan M.S., 2002, Rekayasa Lalu-lintas $I_{2}$ Fakultas Teknik Universitas Syiah Kuala, Darussalam, Banda Aceh.

Bukhari, R.A., 2004, Rekayasa Lalulintas II, Fakultas Teknik Universitas Syiah Kuala, Darussalam, Banda Aceh.

Fidel Miro MStr., 2005, Dasar-dasar Rekayasa Transportasi, jilid 1 Ed. 3. Erlangga, Jakarta.

Volume 2, No. 1, Januari 2016 